\title{
Temporal Stability and Cross-National Consistency of the Dimensional Structure of the Sexual Attraction Questionnaire (SAQ)
}

\author{
Juan Fernández ${ }^{1}, \mathrm{M}^{\mathrm{a}}$ Ángeles Quiroga ${ }^{1}$, Isabel Del Olmo ${ }^{1}$, \\ Chiara Buizza ${ }^{2}$ and Antonio Imbasciati ${ }^{2}$ \\ ${ }^{1}$ Universidad Complutense (Spain) \\ ${ }^{2}$ Università degli Studi di Brescia (Italy)
}

\begin{abstract}
The Sexual Attraction Questionnaire (SAQ) was designed to measure sexual attraction (Fernández, Quiroga, \& Rodríguez, 2006), because the current questionnaires were considered inadequate. The purpose of this research was to test whether the SAQ factors remain meaningful after several years (stability) and whether the Italian version is equivalent to the Spanish one (consistency). Three groups of university students participated: two from Spain $(n=182$ and 255 , respectively) and one from Italy $(n=293)$. The Spanish groups were tested with a 7-year interval (2001-2008). The Italian group was tested in 2008. The main hypotheses were to test, across time interval and countries: (a) factor congruence, (b) predictive power of factors (proportion of variance accounted for), and (c) scale reliability. Sexual attraction typology also was analyzed, within and between countries, to test the validity of the underlying theoretical model. The results obtained show that the SAQ factor structure remains the same, the resulting factors have high predictive power, and the SAQ scales are highly reliable. Sexual dimorphism and sexual attraction typology are highly associated, thus validating the underlying theoretical model.

Keywords: sexual attraction, sexual orientation, sexual typology, factor congruence and stability, cross-national studies.
\end{abstract}

El Cuestionario de Atracción Sexual (CAS) se creó para valorar la atracción sexual (Fernández, Quiroga, \& Rodríguez, 2006) debido a la ausencia de instrumentos específicos. Se pretende analizar ahora si la estructura dimensional del CAS permanece estable con el paso del tiempo y si es semejante en la versión italiana. Participaron tres grupos de estudiantes universitarios: dos españoles (182 y 255) y uno italiano (293). Los datos del primer grupo español se obtuvieron en 2001 y los del segundo en 2008, junto con los del grupo italiano. Las hipótesis se centran en analizar: (a) la congruencia de las estructuras factoriales; (b) el poder predictivo de los factores (proporción de varianza explicada) y (c) la fiabilidad de las escalas del CAS, tanto entre países como entre los dos momentos temporales. Además, para poner a prueba la validez del modelo teórico subyacente, se analiza la semejanza en la tipología de la atracción sexual intra e inter-países. Los resultados muestran que la estructura factorial del CAS se mantiene, sus factores poseen un alto poder predictivo y las escalas gozan de alta fiabilidad. El dimorfismo sexual y la tipología de atracción sexual están altamente relacionados, lo que apoya la validez del modelo teórico subyacente.

Palabras clave: atracción sexual, orientación sexual, tipología sexual, congruencia y estabilidad factorial, estudios interpaíses.

Correspondence concerning this article should be addressed to Juan Fernández Sánchez. Facultad de Psicología, Universidad Complutense, Campus de Somosaguas, 28223 Madrid (Spain). E-mail: jfernandez@psi.ucm.es

The Spanish version of the SAQ can be requested at this e-mail, and the Italian version at: buizza@med.unibs.it 
Within the area of psychology, sexual attraction has generally been considered either a synonym of sexual orientation (until around the 1980s) or one of its components (since the 1980s until the present), but not a dimension that need be studied in itself. Towards the mid- $20^{\text {th }}$ century, the first instruments to assess sexual orientation/attraction appeared, the one elaborated by Kinsey, Pomeroy, and Martin (1948) being the most well-known internationally. At that time, the theory underlying their instrument was a radical change from the dichotomic categorical perspective (heterosexuality vs. homosexuality) that had predominated till then (Sell, 1997). Sexual orientation/attraction was conceived as a dimensional continuum with heterosexuality at one end, homosexuality at the other, and bisexuality somewhere in the middle. The assessment scale ranged from 0 (heterosexuality with no homosexuality) to 6 (homosexuality with no heterosexuality), with the midpoint at 3 (both heterosexuality and homosexuality).

This approach and its assessment of sexual orientation/attraction became the predominant conception in the second half of the $20^{\text {th }}$ century. However, critiques and nuances, both of the theoretical proposals and the derived assessment instrument, were not long coming. Shively and De Decco (1977) elaborated two independent assessment scales: one for heterosexuality and one for homosexuality. Bell and Weinberg (1978) separated sexual behaviors from erotic fantasies, claiming two independent assessment scales. Storms $(1980,1981)$ classified erotic fantasies, and elaborated two independent subscales: eroticism towards males and eroticism towards females. Thus, critique took into account either the object of attraction (men and women: heterosexuality/homosexuality) or the realm in which such attraction was expressed (behaviors and fantasies).

By the eighties, there was a significant change: Sexual attraction became a component of sexual orientation, leading to the elaboration of multidimensional instruments. Thus, Klein and collaborators (Klein, 1990; Klein, Sepekoff, \& Wolf, 1985) designed a sexual orientation instrument to evaluate diverse well-differentiated dimensions: sexual behaviors, sexual attraction, sexual fantasies, emotional and social preferences, self-identification, and heterosexual and homosexual life styles. Coleman (1987) ratified the multidimensionality of sexual orientation - one of whose dimensions was sexual attraction-with a multifactor assessment instrument. In general, the proposed multidimensionality is the result of an attempt to empirically merge some apparently related aspects rather than the logical derivation of a coherent theory of sexual orientation.

In the $1990 \mathrm{~s}$, from the fairly well-consolidated multidimensional approach, new instruments emerged to assess sexual orientation, in which sexual attraction was considered one of the most essential components (Berkey, Perelman-Hall, \& Kurdek, 1990; Sell, 1996). Currently, there are so many sexuality/sexual orientation questionnaires and/or scales that Davis, Yarber, Bauserman, Schreer, and
Davis (1997) published a manual about them, in which sexual attraction was considered a component of the broader construct of sexual orientation.

All these contributions have been the target of pertinent criticism, both of the concepts of sexual orientation or sexual attraction (Greene \& Croom, 2000) and of the assessment instruments (Chung \& Katayama, 1996; Gonsiorek \& Weinrich, 1995; Hansen \& Evans, 1985; Sell, 1996). In fact, there is currently no consensus about the ideal number of dimensions to operationalize the concept of sexual orientation (Friedman et al., 2004).

Due to the lack of a detailed analysis of sexual attraction, there are hardly any specific instruments to assess it. This means that, in research, it is assessed exclusively by means of one or, at most, a very small number of direct questions about the sex to which a person feels attracted (Galliher, Rostosky, \& Hughes, 2004; Giovazolias \& Davis, 2001; Rostosky, Owens, Zimmerman, \& Riggle, 2003).

The lack of an instrument that provides diverse sexual attraction profiles and their corresponding nuances stemming from the analysis of behaviors, thoughts, feelings, or social image, is causing considerable difficulties to the professional practice, particularly in clinical settings, both for specialists and professional associations, and for the patients themselves (Harris, 2001; Ladany et al., 1997; Pope, Keith-Spiegel, \& Tabachnick, 2006).

Fernández, Quiroga, and Rodríguez (2006) attempted to solve some of these problems, both theoretically and by elaborating an instrument to measure sexual attraction. From their theoretical approach, sexual attraction is a dimension that deserves separate and detailed consideration-lacking till now-although it can and should subsequently be integrated as a specific dimension of sexual orientation. The starting point of this approach is apparent sexual dimorphism, whose explanatory mechanisms are relatively well-known. These authors showed that (a) men and women from all societies are capable of differentiating sexual dimorphism with no difficulty, even from a very early age; (b) a high percentage of men feel sexual attraction to women, just as women are attracted to men; (c) some percentage of men and women display dual attraction (towards both sexes); (d) some percentage are attracted to people of the same sex; and (e) a minimal percentage of men and women display no apparent sexual attraction towards either of the sexes (Busseri, Willoughby, Chalmers, \& Bogaert, 2008; D’Augelli \& Patterson, 2001; Diamond, 1993; Fernández, Quiroga, \& Del Olmo, 2006a, 2006b; Lippa, 2007; Omoto $\&$ Kurtzman, 2006). Considering the large percentage of men attracted to women and of women attracted to men, in our time and our societies, these authors infer that sexual attraction can be operationalized by means of two clusters of items, defined either as a function of the object of attraction (attraction to women and to men), or as the specificity of their content (thoughts - cognitive aspectfeelings-emotional aspect-, behaviors-observable 
aspect,- - and social image - hetero-appraisal aspect). These two clusters are inversely related when a whole population is tested. However, if the participants assessed are only bisexual or asexual people, then the relationship between the two clusters would be positive.

On the basis of these assumptions, Fernández and collaborators elaborated an instrument to appraise the dimensional structure of sexual attraction, which they tested with cluster analysis and factor analysis. In this approach, sexual attraction and sexual orientation are analyzed independently, a proposal that was missing till then because sexual attraction was considered just one more component or dimension of sexual orientation (Fernández, Quiroga, \& Rodríguez, 2006). The empirical data clearly supported the proposed dimensional structure of sexual attraction: two clusters of items as a function of the object of attraction emerged. These two clusters can be more specifically operationalized as a bipolar factor or two negatively correlated factors (in both cases, the psychological meaning is the same, although the factor solution is different). Therefore, alternative hypotheses about sexual orientation/attraction were discarded: (a) the dichotomic categorization hypothesis (pre-Kinseyan hypothesis), for obvious reasons of opposition between category and dimension; (b) the hypothesis of unidimensionality (Kinsey et al., 1948), simple bidimensionality (Shively \& De Decco, 1977), and the bidimensional splitting of the double Kinseyan nuance-on the one hand, behaviors and, on the other, fantasies (Bell \& Weinberg, 1978)—, because in all cases, they are based on the Kinseyan assumption and scale, in which heterosexuality is at one end, homosexuality at the other, and bisexuality in the middle, independently of the issue of one or two dimensions; (c) orthogonal bidimensionality (Storms, 1980) because of the obvious incompatibility between the null or almost-null correlation implicit in orthogonality proposed by Storms and the assumption of a very high negative correlation proposed by Fernández el al.; and (d) with regard to the conception of sexual attraction as only one component of the multidimensional sexual orientation (Berkey et al., 1990; Coleman, 1987; Klein et al., 1985), while Fernández et al. do not dispute the multidimensionality of sexual orientation, they clearly postulate two dimensions/clusters for sexual attraction itself.

Given the mobility and dynamism of contemporary societies with regard to sexual attraction, the assessment instrument must be tested to determine whether it retains its original dimensional structure and whether its scores can still be interpreted in the same way. This is the first goal of this work: to analyze the factor invariance of the SAQ (Sexual Attraction Questionnaire) seven years after its creation. Moreover, the SAQ has been translated to Italian, so the second goal was to analyze the factor invariance between the two countries.

The substantial hypothesis of the study is that the dimensional structure of the two clusters will be retained, specifically operationalized either by a bipolar factor or by two inversely related factors, both in the new Spanish participants (group 2008 compared to group 2001), and in the group of Italian participants. The factor structure of the SAQ will be analyzed in the two new groups of participants to verify whether the resulting factor or factors explain at least $75 \%$ of the variance (maintaining their explanatory capacity), whether they still have high internal consistency indexes, and whether there is still a strong association between sexual dimorphism and the four-fold classification of sexual attraction: individuals attracted to both sexes, to none, to men, or to women.

\section{Method}

\section{Participants}

First Spanish group. Data collected in 2001 (Rodríguez, 2002), but published in 2006, along with two subsequent studies (Fernández, Quiroga, \& Rodríguez, 2006).

A group of 182 university students (104 female and 78 male) completed the entire SAQ (22 items) although, for the present study, we only used the responses given to the reduced 16-item version. Students from Pedagogy, a career with a predominance of women (97 females and 8 males) and Technical Engineering, studies chosen preferentially by men ( 70 male and 7 female) were selected. These students were in the first $(39.6 \%)$ and third year of the career $(60.4 \%)$, respectively.

Second Spanish group (2008). Participants were 255 university students: 85 (15 female and 70 male) from Computer Science, 158 (140 female and 18 male) from Psychology, and 12 (all male) from Teaching (Physical Education). Mean age was 22.45 years $(S D=2.58)$. A total of $31(12 \%)$ were first-year students, $18(7 \%)$ were secondyear students, $64(25 \%)$ were in their third year, $108(43 \%)$ in their fourth year, and $34(13 \%)$ were fifth-year students.

Italian group (2008). Participants were 293 university students from Medicine (182 female and 111 male), with a mean age of 21.33 years $(S D=2.60)$. Of this group, $47.4 \%$ were first-year students, $32.8 \%$ were third-year students, and $19.8 \%$ were in their fifth year.

In both Spanish groups, distribution by sex was similar, $\chi^{2}(1, N=437)=.583, p=.445$. The same was true for the comparison of the second Spanish group and Italian one $\chi^{2}(1, N=548)=.102, p=.749$.

\section{Instrument}

The Sexual Attraction Questionnaire (SAQ), in its first and longer version, has 22 elements: 11 operationalize Attraction to Men and the other 11, Attraction to Women. 
The items are supposed to reflect only two objects of attraction - men and women - taking into account: (a) thoughts and fantasies, (b) feelings, emotions, and affects, (c) actions and behaviors, and (d) social image. Each item is rated on a 7-point Likert-type scale, ranging from 1 (totally disagree) to 7 (completely agree). The item scores of Attraction to Men and Attraction to Women define four types of subjects: (a) people attracted to men, with scores higher than the theoretical mean $(M=44)$ in the 11 items of Attraction to Men and scores lower than or equal to the theoretical mean $(M=44)$ in the 11 items of Attraction to Women; (b) people attracted to women, with scores higher than the theoretical mean in the Attraction to Women items and scores lower than or equal to the theoretical mean in the Attraction to Men items; (c) people attracted to both sexes, with scores higher than the theoretical mean in both cases; and (d) people who are not attracted to either sex, with scores lower than or equal to the mean in both cases. The internal consistency values obtained till now are high for both scales: Attraction to Men and Attraction to Women $(\alpha=.98$ and $\alpha=.97$, respectively, in diverse studies and for different versions of the SAQ, 22 items and 17 items). The cluster and factor analyses carried out with the different versions of the SAQ have corroborated the hypothesis of one bipolar factor or-conceptually, the same- two inversely related factors, according to various studies (Fernández et al., 2006b; Fernández, Quiroga, \& Rodríguez, 2006).

In this work, we used the reduced and latest version of the SAQ (the 16-item version) for the three groups, as it best operationalizes the construct of sexual attraction, in view of the cluster analyses, factor analyses, and consistency analyses carried out to date. In this version, the theoretical mean that defines the four groups of subjects is 32 ( 8 items $\times 4$, which is the theoretical mean of each item).

\section{Procedure}

The translation of the SAQ to Italian was carried out by the two Italian authors. A first version was tested with a group of Italian university students, different from the group used in this work. After detailed analysis of each and every item, this version was determined to be ideal for all but 5 items, which were rewritten. All the items of the Italian version of the SAQ currently correspond satisfactorily to the Spanish SAQ in all its versions: 22, 20,17 , and 16 items.

The procedure was similar for all three studies. The 16-item SAQ was administered during normal classes, after obtaining the teachers' and students' permission. The students were requested to complete each item and to be completely sincere in their responses; their anonymity was ensured, as the data would be analyzed as a whole by a university research team (Spanish or Italian).

\section{Data Analysis}

Given the nature of the SAQ items (skewed and/or with excessive kurtosis), we calculated the polychoric correlations by means of the FACTOR program (Lorenzo-Seva \& Ferrando, 2006). Nevertheless, in the three groups studied, the correlation matrix was not positively defined, so we calculated Pearson correlations. We used the FACTOR program to analyze the SAQ factor structure, with principal axes extraction method and oblique rotation (promin). For all the groups, we specified, a priori, two factors and we selected the procedure parallel analysis, using marginally bootstrapped samples to determine the number of dimensions. This program also calculates Mardia's coefficient to appraise possible skewness and/or multivariate kurtosis, the reliability of the rotated factors, and the indexes of factor simplicity (Erceg-Hun \& Mirosevich, 2008; Lorenzo-Seva, 2003).

After exploratory factor analyses and to analyze whether the SAQ has a stable and consistent factor structure, we analyzed configural and metric invariance (Lievens, Reeve, \& Heggestad, 2007; Vandenberg \& Lance, 2000). For configural invariance (whether the series of items reflects the same latent construct in the diverse groups), we used Tucker's congruence coefficient $\left(r_{c}\right)$, following the recommendations of Jensen (1998, pp. 99-100). An $r_{c}$ value of .90 is considered a high degree of factor similarity, whereas a value over .95 means that the factors are practically identical. To determine metric invariance (whether each item loads with the same magnitude on the factor in the diverse groups), we calculated the intraclass correlation coefficient, as recommended by Pinneau and Newhouse (1964).

Cronbach's alpha was used to analyze reliability of the instrument. Lastly, to analyze the association between sexual dimorphism and the fourfold sexual attraction typology, a contingency table analysis was performed to obtain the statistics $\chi^{2}$ and C. For the latter, we calculated Sakoda's correction (C*; Agresti, 1996).

\section{Results}

\section{Descriptive Statistics}

In Table 1 are displayed the means, standard deviations, and contrast statistics of the 16 items of the SAQ in the three groups analyzed. The results show that the two Spanish groups are practically equivalent in the means of the items. There was only one statistically significant difference in Item 2. To understand its meaning, we performed a contingency table analysis. The standardized residuals were only equal to or higher than \pm 2 in score 1 , indicating that there were more participants who chose this option in the 2001 group than in the 2008 group. 
Table 1

Means, Standard Deviations and Contrast Statistics for the Three Groups Analyzed

\begin{tabular}{|c|c|c|c|c|c|c|c|c|c|}
\hline & \multirow[b]{2}{*}{ Items $^{c}$} & \multicolumn{2}{|c|}{ Spain 2001} & \multicolumn{2}{|c|}{ Spain 2008} & \multicolumn{2}{|c|}{ Italy 2009} & \multirow[t]{2}{*}{$\mathrm{B}-\mathrm{F}^{\mathrm{a}}$} & \multirow[t]{2}{*}{$\mathrm{B}-\mathrm{F}^{\mathrm{b}}$} \\
\hline & & $M$ & $S D$ & $M$ & $S D$ & $M$ & $S D$ & & \\
\hline \multirow{8}{*}{ Attraction to Men } & 2 & 3.8 & 2.37 & 4.42 & 2.2 & 3.8 & 2.11 & $7.64 * *$ & $11.154 * *$ \\
\hline & 8 & 4.46 & 2.88 & 4.53 & 2.77 & 4.53 & 2.79 & 0.079 & 0.001 \\
\hline & 9 & 3.7 & 2.49 & 3.91 & 2.37 & 3.39 & 2.19 & 0.83 & $7.17 * *$ \\
\hline & 13 & 4.17 & 2.62 & 4.53 & 2.45 & 3.94 & 2.34 & 2.106 & $8.14 * *$ \\
\hline & 14 & 4.47 & 2.82 & 4.7 & 2.75 & 4.33 & 2.63 & 0.693 & 2.53 \\
\hline & 15 & 4.53 & 2.83 & 4.68 & 2.77 & 4.66 & 2.75 & 0.323 & 0.013 \\
\hline & 16 & 3.76 & 2.46 & 3.91 & 2.38 & 3.68 & 2.32 & 0.407 & 1.39 \\
\hline & 21 & 4.24 & 2.64 & 4.4 & 2.39 & 4.38 & 2.59 & 0.442 & 0.01 \\
\hline \multirow{8}{*}{ Attraction to Women } & 1 & 2.73 & 2.41 & 2.67 & 2.17 & 2.56 & 2.16 & 0.051 & 0.384 \\
\hline & 3 & 2.79 & 2.44 & 2.62 & 2.16 & 2.89 & 2.28 & 0.567 & 2.152 \\
\hline & 4 & 3.16 & 2.49 & 3.45 & 2.31 & 3.16 & 2.45 & 1.529 & 2.139 \\
\hline & 11 & 3.24 & 2.75 & 3.34 & 2.53 & 3.22 & 2.62 & 0.148 & 0.31 \\
\hline & 12 & 3.41 & 2.4 & 3.85 & 2.17 & 2.91 & 2.11 & 3.84 & $26.099 * * *$ \\
\hline & 17 & 3.25 & 2.48 & 3.49 & 2.38 & 3.08 & 2.36 & 1.05 & $4.108^{*}$ \\
\hline & 18 & 3.15 & 2.71 & 3.23 & 2.49 & 2.98 & 2.41 & 0.106 & 1.475 \\
\hline & 20 & 3.25 & 2.83 & 3.45 & 2.82 & 3.16 & 2.74 & 0.502 & 1.415 \\
\hline
\end{tabular}

Note: The Brown-Forsythe (B-F) statistic was used as it is more robust when homocedasticity is lacking. ${ }^{a}$ Comparison of Spanish groups 2001-2008. ${ }^{\mathrm{b}}$ Comparison of Spanish and Italian 2008 groups. ${ }^{\mathrm{c}}$ The numbers of the original 22-item version SAQ are maintained $* p<.05$. ** $p<.01 . * * * p<.001$.

In the comparison of the Spanish and Italian groups, 3 items from the Attraction to Men Scale and 2 from the Attraction to Women Scale had significantly different means. The contingency table analysis, via the standardized residuals, showed that: (a) in Item 2, fewer Italian participants chose score 7 than Spaniards; (b) in Item 9, none of the residuals was equal to or higher than \pm 2 ; in any case, accepting a limit of \pm 1.8 , fewer Italians than Spaniards chose score 7; (c) also in Item 13, fewer Italians than Spaniards chose score 7. All these differences reflect only slight nuances in the extreme response tendencies; that is, when fewer participants chose score 7 , it is because some of them chose score 6. In both cases (score 7 or 6), the participant agreed with the content of the item. There are differences in score 1 because some of the participants chose score 2 but, in both cases, they disagreed with the item. These slight differences do not reflect true discrepancies in the response tendencies on the SAQ between the Italian and the Spanish participants. The similarity of the frequency distributions according to sex of the Italian and Spanish groups for the remaining items is displayed in Table 2.

Items 12 and 17 deserve special mention. In Item 17, both groups have the same response tendencies, $\chi^{2}(6, N=$ $548)=10.03, p=.12$; therefore, the probability of the mean contrast was only .04. In item 12, the Italian and Spanish participants displayed different response tendencies, as shown by the frequency distribution of both groups and the standardized residuals included in Table 3.
The results of this table show that the Italian participants were more polarized in their disagreement with this item than the Spaniards. Taking into account the content of this item ("I find some female TV presenters very erotic"), we analyzed the men's and women's response tendencies. The results indicated that the differences between the Italian and the Spanish participants are found in women, $\chi^{2}(6, N$ $=337)=45.92, p<.001$, not in men, $\chi^{2}(6, N=211)=$ $8.09, p=.23$. In other words, many more Italian females disagreed with the item than did Spanish females; on the other hand, more Spanish females agreed with the item than did Italian females (scores 4, 5, and 6).

\section{Stability of the Factor Structure of the SAQ (Spanish 2001-2008 groups)}

For both groups, Mardia's (1970) coefficient revealed excessive multivariate kurtosis, but adequate skewness. This is not surprising because the SAQ items are designed so that people will display the degree to which men and women are the object of their sexual attraction, that is, they are designed to obtain polarized responses. Future research with the SAQ should take into account the expected excessive kurtosis because it affects variances.

In the analysis of the factor structure of the SAQ with the 2008 Spanish group, the $K M O$ index obtained was .97 , fully satisfactory and the same as that obtained in the 2001 group (.97). 


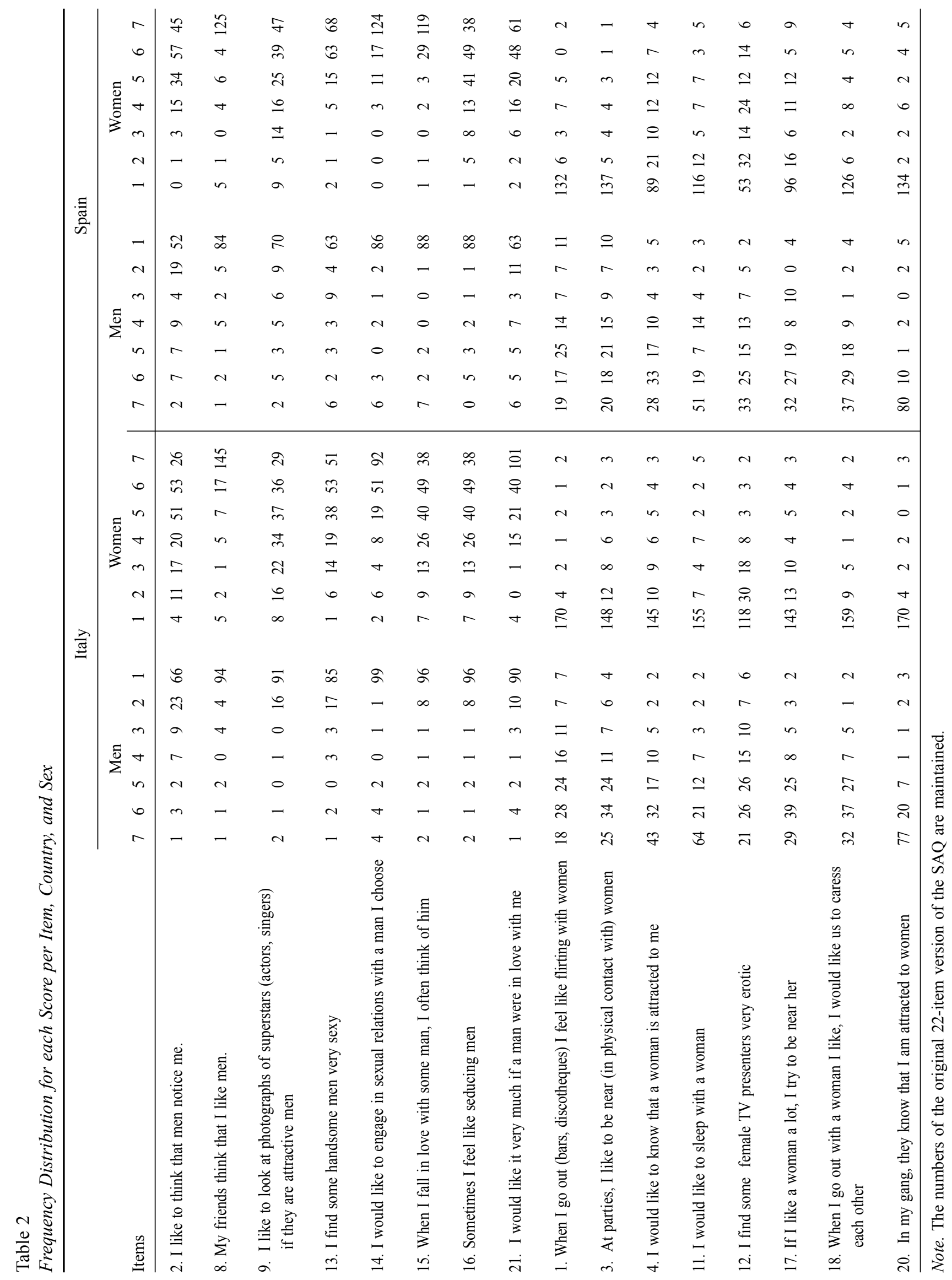


Table 3

Frequency Distribution and Standardized Residuals per Country for Item 12

\begin{tabular}{cccc}
\hline & Italy & Spain & Total \\
\hline Score & & & \\
1 & 124 & 55 & 179 \\
& 2.9 & -3.1 & \\
2 & 37 & 37 & 74 \\
& -0.4 & 0.4 & 49 \\
3 & 28 & 21 & \\
& 0.4 & -0.4 & 60 \\
4 & 23 & 37 & 56 \\
5 & -1.6 & 1.7 & 68 \\
& 29 & 27 & \\
6 & -0.2 & 0.2 & 62 \\
& 29 & 39 & \\
7 & -1.2 & 1.3 & 548 \\
\hline \multirow{2}{*}{ Total } & 23 & 1.9 & \\
\hline
\end{tabular}

Note. Standardized residuals are in italics.

The results of the principal axes factor analysis (loadings and communality) of both Spanish groups are included in Table 4. In the first study, a single bipolar factor that explained $82.48 \%$ of the variance was obtained. In the second study, we found two inversely related factors (-.79) that explained $81.23 \%$ of the variance. In both studies, the communalities of all the items were high. The simplicity indexes of the factor solution (Lorenzo-Seva, 2003) were .60 (percentile 100) and .65 (percentile 100) for 2001 and 2008 , respectively, which indicates that the factor solutions obtained can be considered the simplest. We used LorenzoSeva's simplicity index instead of Bentler's more wellknown index because it does not depend on factor scale.

Congruency analysis of the factor solutions was performed comparing the factor obtained in the 2001 group and the first unrotated factor of the 2008 group (see Table 4). The value of the congruence index was .99 , which shows that factors are identical and, therefore, configural invariance exists between the two temporal moments. Moreover, the intraclass correlation coefficient between these two factors was .99 , reflecting metric invariance between both solutions.

The internal consistency of the two scales that comprise the SAQ was also maintained: Attraction to Women: .98 (2001) and .97 (2008); Attraction to Men: .98 (2001) and .97 (2008).

With regard to the relation of the SAQ with sexual dimorphism, Table 5 (Spain 2001 and Spain 2008) displays the predicted association between sexual dimorphism and sexual attraction (women mostly feel attracted to men and men to women: (a) 2001: $\chi^{2}(3, N=182)=149.47, p<$ $.001, C=.67, C^{*}=.96$; and (b) 2008: $\chi^{2}(3, N=255)=$ 203.53, $p<.001, C=.67, C^{*}=.94$.
A fact that should be taken into account is that when samples of participants are not representative, the minority groups - regarding sexual attraction - can vary considerably, although within a small range if compared to the two majority groups: people attracted to men or to women. Nevertheless, in the two groups studied, the standardized residuals of each cell show the same direction (sign) and similar magnitude. Moreover, classification of subjects according to type of sexual attraction they display between both temporal moments was similar, $U=21585, z=-1.43$, $p=.15$. Therefore, with regard to sexual dimorphism, the association with the typology of sexual attraction was still statistically significant and of the same magnitude.

\section{Cross-national Consistency of the Factor Structure of the $S A Q$}

As with the former analysis, Mardia's coefficient also revealed excessive multivariate kurtosis but adequate skewness in both groups: Spanish and Italian of 2008.

In the analysis of the factor structure of the SAQ with the Italian group, the $K M O$ index obtained was .97 , fully satisfactory and the same as that obtained in the Spanish 2008 group (.97).

The results of the principal axes factor analysis (loadings and communality) of the Italian group are included in Table 4 (the three last columns).

In the Italian group, we found two inversely related factors (-.82) that explain $84.09 \%$ of the variance. In the Spanish group, as mentioned, there were also two inversely related factors that explain a very similar proportion of variance, although slightly lower (81.23\%). The communality indexes in both groups (Spanish and Italian) were very high. In both groups, Item 12 presented a lower communality that, nevertheless, was $60 \%$ (.595 and .696, respectively). This is congruent with the analyses presented in the Descriptive Statistics section, where we mentioned the different response tendencies in the Spanish and Italian participants.

The simplicity indexes of the factor solution were .57 (Italian group) and .65 (2008 Spanish group), both in the 100 percentile, which indicates that the factor solutions obtained can be considered the simplest.

The congruence index was .99 for both factors. In both cases, it can be said that the factors are identical and, therefore, the configuration of the SAQ is invariant across the two countries. Moreover, the intraclass correlation coefficient between the first two factors was .97 , and between the second two, it was .97 . These results reflect the metric invariance between the two solutions.

The internal consistency of the two SAQ scales was also maintained in the Italian version: Attraction towards Women: .97 and .97 (Spanish participants); Attraction towards Men: 98 and .97 (Spanish group).

Lastly, regarding the relation of the SAQ with sexual dimorphism, Table 5 (Italy, 2008) shows the predicted 


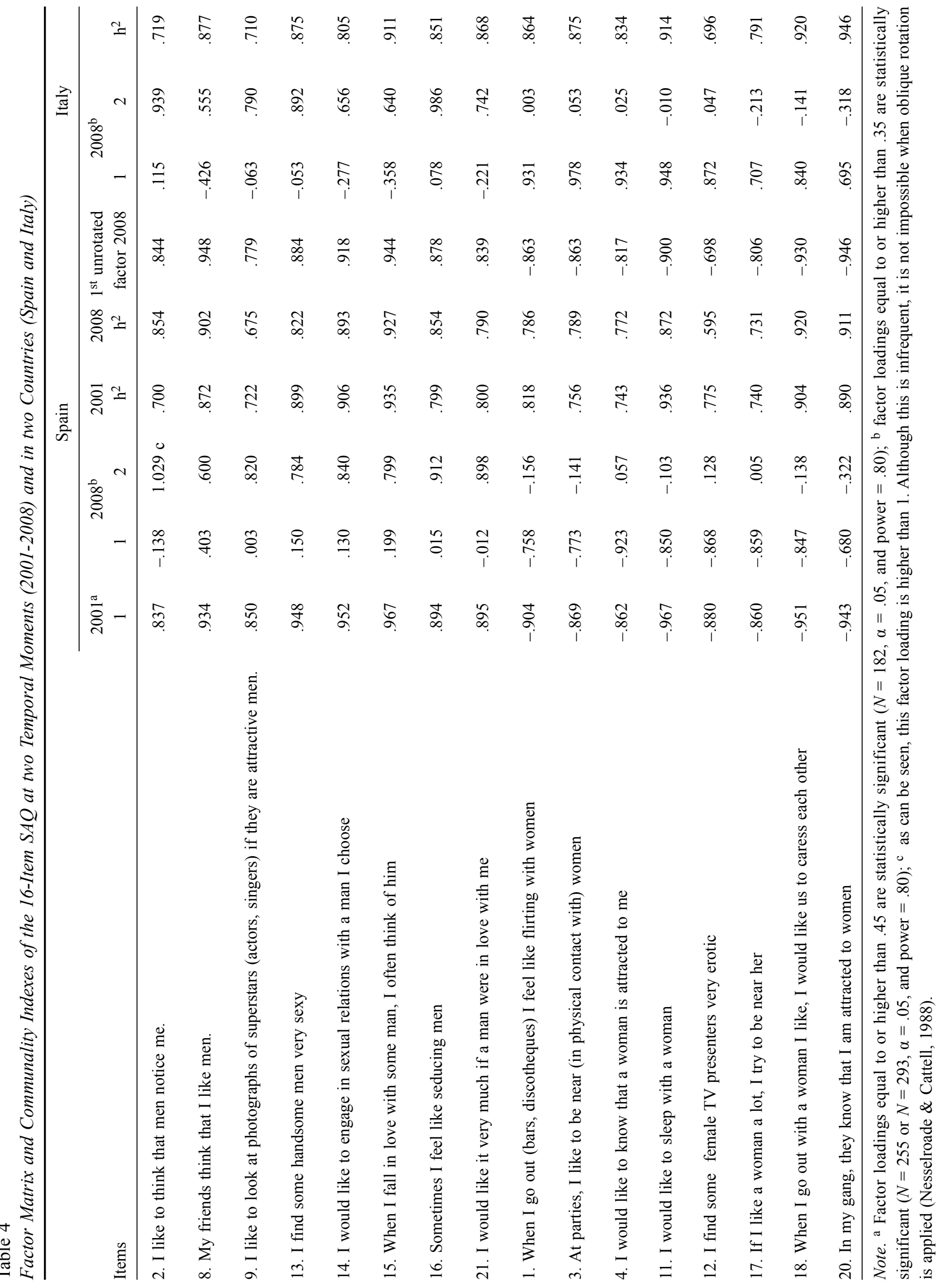


Table 5

Relation between Sexual Dimorphism and Sexual Attraction for all the Assessed Groups

\begin{tabular}{|c|c|c|c|c|c|}
\hline & & & \multicolumn{3}{|c|}{ Sexual dimorphism } \\
\hline & & & Women & Men & Total \\
\hline \multirow{9}{*}{ Spain 2001} & \multirow{9}{*}{ Typology of sexual attraction } & \multirow{2}{*}{ To neither sex } & 5 & 2 & 7 \\
\hline & & & .5 & -.6 & \\
\hline & & \multirow{2}{*}{ To women } & 0 & 67 & 67 \\
\hline & & & -6.2 & 7.1 & \\
\hline & & \multirow{2}{*}{ To men } & 99 & 7 & 106 \\
\hline & & & 4.9 & -5.7 & \\
\hline & & \multirow{2}{*}{ To both sexes } & 0 & 2 & 2 \\
\hline & & & -1.1 & 1.2 & \\
\hline & & Total & 104 & 78 & 182 \\
\hline \multirow{9}{*}{ Spain 2008} & \multirow{9}{*}{ Typology of sexual attraction } & \multirow{2}{*}{ To neither sex } & 1 & 4 & 5 \\
\hline & & & -1.2 & 1.5 & \\
\hline & & \multirow{2}{*}{ To women } & 3 & 86 & 89 \\
\hline & & & -6.9 & 8.6 & \\
\hline & & \multirow{2}{*}{ To men } & 141 & 6 & 147 \\
\hline & & & 5.5 & -6.8 & \\
\hline & & \multirow{2}{*}{ To both sexes } & 10 & 4 & 14 \\
\hline & & & .5 & -.6 & \\
\hline & & Total & 155 & 100 & 255 \\
\hline \multirow{9}{*}{ Italy 2008} & \multirow{9}{*}{ Typology of sexual attraction } & \multirow{2}{*}{ To neither sex } & 5 & 4 & 9 \\
\hline & & & -.2 & .3 & \\
\hline & & \multirow{2}{*}{ To women } & 2 & 101 & 103 \\
\hline & & & -7.7 & 9.9 & \\
\hline & & \multirow{2}{*}{ To men } & 171 & 3 & 174 \\
\hline & & & 6.1 & -7.7 & \\
\hline & & \multirow{2}{*}{ To both sexes } & 4 & 3 & 7 \\
\hline & & & -.2 & .2 & \\
\hline & & Total & 182 & 111 & 293 \\
\hline
\end{tabular}

Note. Standardized residuals are in italics.

association, which is similar to that of the Spanish group: $\chi^{2}(3, N=293)=255.41, p<.001, C=.68, C^{*}=.96$.

In the two groups, Spanish and Italian, the standardized residuals of each cell show the same direction (sign) and similar magnitude. Moreover, classification of subjects according to the type of sexual attraction displayed was similar in both countries, $U=36002, z=.84, p=.40$. Therefore, the association of the sexual attraction typology with sexual dimorphism obtained with the Italian version of the SAQ is also statistically significant and of the same magnitude.

\section{Discussion}

In view of these data and regarding the substantial hypothesis that guides this work, the SAQ, in its reduced 16-item version, maintains the same structure it had when created, two inversely related clusters that are operationalized either by one bipolar factor (2001 participants) or by two negatively correlated factors (2008 participants). Therefore, it does not seem that time (more than 5 years) or nationality (Spanish or Italian) substantially modifies the dimensional structure of the SAQ. Furthermore, the cluster analyses with the three types of participants, prior to the factor analyses, yielded practically identical results: two clear clusters. We have not presented these results here to avoid redundancy and because they are just confirmation of the already published results, although this time, with only 16 items in the scale (Fernández, Quiroga, \& Rodríguez, 2006).

This empirical support leads to a reflection about the other alternatives that, from the broader area of sexual orientation, have been proposed throughout the $20^{\text {th }}$ century. It is obvious that two clear groups can be established to categorize the different alternative hypotheses. On the one 
hand, those focused on sexual orientation as one, or at most, two dimensions and, on the other hand, the one that considers sexual orientation from a multidimensional approach.

With regard to the first group, the dimensional structure operationalized by the SAQ is clearly different from the dichotomic categorization that was typical of the first half of the past century: heterosexuality versus homosexuality (Sell, 1997), if only because individuals who are attracted to both sexes or to neither of them now fit. Likewise, the SAQ is different from the Kinseyan unidimensionality (Kinsey et al., 1948) because, among other things, bisexuality can hardly be assessed as the mid-point of a scale. Nor is it the same as the proposed bidimensionalitieshomosexuality on one scale and heterosexuality on another (Shively \& De Decco, 1977) — or behaviors at one end and fantasies at the other (Bell \& Weinberg, 1978)-or orthogonal bidimensionality (Storms, 1980, 1981). The reasons for these three cases are clear: In the first two, due to their Kinseyan conception-a continuum with homosexuality at one end and heterosexuality at the other, and bisexuality in the center-simply adding a split of the scales - heterosexuality at one end and homosexuality at the other-or a split of their content-behaviors at one end and fantasies at the other. In the last case, because orthogonality is simply opposed to an inversely related bidimensionality.

What happens when sexual orientation is regarded from multidimensionality, which should include sexual attraction? Up till now, the structure of this dimension has not been specified, although it is assumed that it must be a single dimension. There are no objections to the multidimensionality of sexual orientation - within which sexual attraction could be included - as long as the nature of the dimensionality of sexual attraction is specified beforehand. As we have seen, it consists of two inversely related clusters or factors (Spanish and Italian 2008 groups), or a single bipolar factor (Spanish 2001 group), as revealed from the theoretical proposals underlying the elaboration of the SAQ.

In comparative studies, both from the temporal and situational viewpoints, it is important to analyze the consistency of the dimensions obtained in the most diverse groups of participants. In our case, the value of the congruence index between factors is adequate, because it is approximately .99 , that is, over .95 , the value at which the factors are considered identical. In fact, the values of the intraclass correlations show that the items that load on each factor have practically identical weights. Therefore, the SAQ, both in its Spanish and its Italian version, continues to yield the two clusters foreseen from its theoretical conception; they are inversely related, and the items that operationalize them load on them with the same weight.

The results also reveal that the factors that operationalize the structure of the SAQ maintain their explanatory capacity.
In all cases, the proportion of explained variance is above $80 \%$. Considered in its own or comparing it to other instruments from similar spheres, this proportion is obviously satisfactory (Davis et al., 1997). One could certainly ask what the $20 \%$ of the unexplained variance means. The answer is not easy. In fact, we have currently no clues about the course to follow, although one could imagine that certain personality aspects lead participants to establish nuances in their responses to some items. This topic may deserve to be investigated later on.

With regard to internal consistency, as foreseen, both scales (Attraction to Women and Attraction to Men) show high reliability, reflected in the high Cronbach's alpha values obtained in different temporal (2001 and 2008) and social circumstances (Italian and Spanish students from very diverse careers).

Concerning the relation between sexual dimorphism and the typology of sexual attraction, both within- and between-countries, the data again provide strong support to the model, that is, most men feel attracted to women and most women are attracted to men, and there is always a minority, statistically speaking, that is attracted to both sexes or to neither sex. As the samples of participants are not representative, the frequencies of these minority groups have practically no value for inferring the true number of these individuals in the diverse populations, except to indicate that there are sexual attractions that are different from those of the two majority groups in all or almost all groups susceptible to being studied. Nevertheless, as an assessment instrument that provides valid and reliable information about sexual attraction, the SAQ could be a useful approach to gather data in representative samples about fairly realistic quantities of the different types of people: individuals attracted to both sexes, to men, to women, or to neither sex.

The fact that the groups assessed were not representative samples of the population could be used as an argument against the proposed model. However, the challenge should be falsification, not verification, because it is very difficult to work with representative samples (due to the enormous cost involved). The goal of falsification implies finding unbiased groups of participants (which would therefore include homosexuals, heterosexuals, bisexuals, and people not attracted to either of the sexes) in which a structure of two inversely related clusters (attraction to men and attraction to women), that can be factorially specified either as one bipolar factor or as two inversely related factors, would not be obtained. Only in such a case would doubt be case on the model. This will be our challenge in the immediate future.

From the professional viewpoint, there is a big difference between the data collected by means of one or two questions about sexual orientation (the most frequent procedure till now) and those obtained by means of the SAQ. In the latter case, we can elaborate a profile of each and every subject 
as a function of their scores in the items related to thoughts, feelings, behaviors, and social image. Once an individual's corresponding profile is obtained, the enormous and rich variability of differentiating nuances within each one of the four categories can be confirmed. There are considerable differences in thoughts, feelings, behaviors, or social image as a function of the object of one's sexual attraction. This within-categorical variability is completely lost if one asks the participants to respond only and exclusively to one or two questions about their sexual attraction. The most that can be achieved with this information is a very simple between-categorical classification. This practical and professional distinction (capturing the within-categorical variability) may mark the differences in the procedures used till now to appraise sexual attraction (considered just one more dimension of sexual orientation). Likewise, this detailed within-categorical information will allow us to observe the variations over people's life span, in their thoughts, feelings, behaviors, or social image, or in all these aspects simultaneously.

\section{References}

Agresti, A. (1996). Introduction to categorical data analysis. New York: Wiley.

Bell, A. P., \& Weinberg, M. S. (1978). Homosexualities. New York: Simon \& Schuster.

Berkey, B. R., Perelman-Hall, T., \& Kurdek, L. A. (1990). The Multidimensional Scale of Sexuality. Journal of Homosexuality, 19, 67-87.

Busseri, M. A., Willoughby, T., Chalmers, H., \& Bogaert, A. (2008). On the association between sexual attraction and adolescent risk behaviour involvement: Examining mediation and moderation. Developmental Psychology, 44, 69-80.

Chung, Y. B., \& Katayama, M. (1996). Assessment of sexual orientation in lesbian/gay/bisexual studies. Journal of Homosexuality, 30, 49-62.

Coleman, E. (1987). Assessment of sexual orientation. Journal of Homosexuality, 14, 9-24.

D'augelli, A. R., \& Patterson, C. J. (2001). Lesbian, gay, and bisexual identities and youth: Psychological perspectives. New York: Oxford University Press.

Davis, C. M., Yarber, W. L., Bauserman, R., Schreer, G., \& Davis, S. L. (1997). Handbook of sexuality-related measures. Thousand Oaks, CA: Sage.

Diamond, M. (1993). Homosexuality and heterosexuality in different populations. Archives of Sexual Behavior, 22, 291-310.

Erceg-Hun, D. M., \& Mirosevich, V. M. (2008). Modern robust statistical methods. An easy way to maximize the accuracy and power of your research. American Psychologist, 63, 591501.

Fernández, J., Quiroga, M. A., \& Del Olmo, I. (2006a). Is there any relationship between sexual attraction and gender typology? The Spanish Journal of Psychology, 9, 3-9.
Fernández, J., Quiroga, M. A., \& Del Olmo, I. (2006b). Is sexual attraction independent of the instrumental and expressive traits? The Spanish Journal of Psychology, 9, 162-179.

Fernández, J., Quiroga, M. A., \& Rodríguez, A. (2006). Dimensionalidad de la atracción sexual. Psicothema, 18, 392399.

Friedman, M. S., Silvestre, A. J., Gold, M. A., Markovic, N., SavinWilliams, R. C., Huggins, J., \& Sell, R. L. (2004). Adolescents define sexual orientation and suggest ways to measure it. Journal of Adolescence, 27, 303-317.

Galliher, R.V., Rostosky, S. S., \& Hughes, H. K. (2004). School belonging, self-esteem, depressive symptoms in adolescents: An examination of sex, sexual attraction status, and urbanicity. Journal of Youth and Adolescence, 33, 235-245.

Giovazolias, T., \& Davis, P. (2001). How common is sexual attraction towards clients? The experiences of sexual attraction of counselling psychologists toward their clients and its impact on the therapeutic process. Counselling Psychology Quarterly, 14, 281-286.

Gonsiorek, J. C., \& Weinrich, J. D. (1995). Definition and measurement of sexual orientation. Suicide and Life Threatening Behavior, 25, 40-51.

Greene, B., \& Croom, G. L. (Eds.) . (2000). Education, research, and practice in lesbian, gay, bisexual, and transgendered psychology: A resource manual (Vol. 5). Thousand Oaks, CA: Sage.

Hansen, C. E., \& Evans, A. (1985). Bisexuality reconsidered: An idea in pursuit of a definition. Journal of Homosexuality, 11, 1-6.

Harris, S. M. (2001). Teaching family therapists about sexual attraction in therapy. Journal of Marital and Family Therapy, 27, 123-128.

Jensen, A. R. (1998). The $g$ factor. The science of mental abilities. Wesport, CN: Praeger.

Kinsey, A. C., Pomeroy, W. B., \& Martin, C. E. (1948). Sexual behavior in the human male. Philadelphia: Saunders.

Klein, F. (1990). The need to view sexual orientation as a multivariable dynamic process: A theoretical perspective. In D. P. McWhirter, S. A. Sanders, \& J. M. Reinisch (Eds.), Homosexuality/heterosexuality: Concepts of sexual orientation (pp. 277-282). New York: Oxford University Press.

Klein, F., Sepekoff, B., \& Wolf, T. J. (1985). Sexual orientation: A multi-variable dynamic process. Journal of Homosexuality, $11,35-49$.

Ladany, N., O'Brien, K. M., Hill, C. E., Melincoff, D. S., Knox, S., \& Petersen, D. A. (1997). Sexual attraction toward clients, use of supervision, and prior training: A qualitative study of predoctoral psychology interns. Journal of Counselling Psychology, 44, 413-424.

Lievens, F., Reeve, C. L., \& Heggestad, E. D. (2007). An examination of psychometric bias due to retesting on cognitive ability tests in selection settings. Journal of Applied Psychology, 92, 1672-1682.

Lippa, R. A. (2007). The relation between sex drive and sexual attraction to men and women: A cross-national study of heterosexual, bisexual, and homosexual men and women. Archives of Sexual Behavior, 36, 209-222. 
Lorenzo-Seva, U. (2003). A factor simplicity index. Psychometrika, 68, 49-60.

Lorenzo-Seva, U., \& Ferrando, P. J. (2006). FACTOR: A computer program to fit the exploratory factor analysis model. Behavioral Research Methods, Instruments and Computers, 38, 88-91.

Mardia, K. V. (1970). Measures of multivariate skewness and kurtosis with applications. Biometrika, 57, 519-530.

Nesselroade, J. R., \& Cattell, R. B. (Eds.). (1988). Handbook of multivariate experimental psychology ( $2^{\text {nd }}$ ed.). New York: Plenum Press.

Omoto, A. M., \& Kurtzman, H. S. (2006). Sexual orientation and mental health. Examining identity and development in lesbian, gay and bisexual people. Washington DC: American Psychological Association.

Pinneau, S. R., \& Newhouse, A. (1964). Measures of invariance and comparability in factor analysis for fixed variables. Psychometrika, 29, 271-281.

Pope, K. S., Keith-Spiegel, P., \& Tabachnick, B. G. (2006). Sexual attraction to clients: The human therapist and the (sometimes) inhuman training system. Training and Education in Professional Psychology, 8, 96-111. (Reprint from American Psychologist, 1986, 41, 147-158).

Rodríguez, A. (2002). Discriminación de la identidad de género $y$ de la orientación sexual en el periodo de la primera juventud.
Unpublished doctoral dissertation. Universidad Complutense de Madrid.

Rostosky, S. S., Owens, G., Zimmerman, R. S., \& Riggle, E. D. B. (2003). Associations among sexual attraction status, school belonging, and alcohol and marijuana use in rural high school students. Journal of Adolescence, 26, 741-751.

Sell, R. L. (1996). The Sell Assessment of Sexual Orientation: Background and scoring. Journal of Gay, Lesbian, and Bisexual Identity, 1, 295-310.

Sell, R. L. (1997). Defining and measuring sexual orientation: A review. Archives of Sexual Behavior, 26, 643-658.

Shively, M. G., \& De Decco, J. P. (1977). Components of sexual identity. Journal of Homosexuality, 2, 41-48.

Storms, M. D. (1980). Theories of sexual orientation. Journal of Personality and Social Psychology, 38, 783-792.

Storms, M. D. (1981). A theory of erotic orientation development. Psychological Review, 88, 340-353.

Vandenberg, R. J., \& Lance, C. E. (2000). A review and synthesis of the measurement invariance literature: Suggestions, practices and recommendations for organizational research. Organizational Research Methods, 3, 4-70.

Received October 8, 2008 Revision received January 22, 2009 Accepted January 31, 2009 